\title{
Facilitating Administrative Decision-Making using Decision Support Systems
}

\author{
Elaine Byrne \\ Department of Informatics, University of Pretoria \\ Department of Epidemiology and Public Health Medicine \\ Royal College of Surgeons in Ireland \\ Dublin, Ireland \\ elainebyrne2@rcsi.ie
}

\author{
Hossana Twinomurinzi \\ Department of Informatics, University of Pretoria \\ Pretoria, South Africa \\ twinoh@up.ac.za
}

\begin{abstract}
Governments in developing countries (DC) are constantly under pressure to achieve participatory governance using Information and Communication Technology (ICT). Although many articles have appeared that clearly underscore the potential of ICT to achieve participatory governance, egovernance, most are focused on how e-governance will lead to democratic reforms. It is hard to find articles that consider how e-governance makes administrative decision-making more efficient. Administrative decision-making refers to the continual process through which government administrators make fair, impartial and just decisions. This paper based on interpretive field research experiences from South Africa proposes an ICT facilitated decision-making approach between government administrators and DC communities for participatory egovernance. The findings make a contribution to government practice and to the Information Systems field of e-governance. For government practice, the theoretically informed approach indicates encouraging results for participatory feedback on existing government services and for strengthening communication channels and capabilities during the process of reaching mutually agreeable decisions with DC communities. For e-governance, the paper proposes an approach that considers the greater antecedents of the occasional democratic participation, the essential day-to-day necessity of administrative decisionmaking using ICT.
\end{abstract}

Keywords- Policy implementation; administrative justice; administrative decision making; decision support systems; participatory e-governance

\section{INTRODUCTION}

DCs have to constantly deal with a number of 'wicked' problems such as unemployment, poverty, crime and the emigration of the scanty skilled labour to developed countries. A wicked problem is a type of problem that defies conventional problem solving techniques and has the effect of getting worse with every attempt to solve it[1]. Wicked problems are often managed rather than solved. Managing wicked problems needs more than conventional structured problem solving techniques.

Previous research posits that DCs would be able to deal with their wicked problems by adopting similar approaches to participative governance as developed countries, further suggesting the use of ICT [2]. The emphasis has however only been on achieving e-governance as a means for democratic reforms and transparency in decisions. The important ability for DC communities to continually participate with government administrators in an effort to influence administrative decision-making processes prior to decisions being reached has hardly been investigated.

This paper, based on research experiences in South Africa, sought to understand the role of ICT in facilitating participatory administrative decision-making. Administrative decisionmaking broadly falls under administrative law. Administrative law makes provision for people to receive an opportunity to question and review government decisions, and the processes leading up to the decisions, for services that they are entitled to or that they perceive they are entitled to [3].

In South Africa, administrative law is promulgated under the Promotion of the Administrative Justice Act of 2000 (PAJA). The PAJA was enacted with the primary purpose of promoting fair and impartial administrative decision-making. PAJA states that everybody has the right to fair, lawful and reasonable administrative action, and that reasons should be given to people in cases where administrative decisions affect them negatively. PAJA brings into effect the right enshrined in the Constitutional Bill of Rights to 'just' administrative action. The government has however struggled to implement the PAJA, and many other policies, since inception primarily citing human capacity problems [4-9].

One of the fundamental aspects of addressing fair and transparent administrative decision-making is the existence of an open forum for dialogue between people and government administrators. Such a forum requires the collation of multiple perspectives which perspectives can be further discussed participatively until mutual consensus is arrived at. In South Africa however, largely as a result of the apartheid period, significant divisions were created within society. The divisions continue to have a considerable impact on the functioning of public service institutions, create tensions between different races and ethnic groups, and lead to a low trust within society of public institutions [10]. Thus, although the first democratic election of 1994 and the 1996 constitution initiated a process of decentralization and increased accountability, they brought with them profound demands on the government as well as the citizens for radical transformation [11].

This paper examines the creation of such an ICT facilitated administrative decision-making forum for the exchange of 
respectful dialogue between government administrators and DC communities with the purposes of:

- $\quad$ increased understanding of rights and responsibilities and hence generation of realistic expectations;

- making administrative decision-making more reasonable, fair and impartial as required in the PAJA, and;

- minimising the load of increased participation.

This article argues that a more theoretically informed implementation strategy complemented by the capabilities of Information and Communication Technology (ICT) could have a profound effect not only regarding peoples' awareness of their rights and the taking of action accordingly, but also in terms of the capacity of the administrators to act in a manner adhering to the PAJA.

A brief discussion of PAJA follows and in Section 3 describes the conventional approach to DSS and a more holistic approach which is needed if DSS are to be used to assist in eliciting multiple perspectives which can inform action. Section 4 describes the research project where such an approach to DSS was adopted. Section 5 concludes with how the implementation of the PAJA can benefit from taking a broad holistic view to decision-making through using DSS.

\section{The Promotion of the Administrative Justice ACT}

Despite heavy investments, public service delivery as a collaborative approach still remains a significant challenge in South Africa [8, 9, 12, 13]. In most instances, both the government administrators and people do not know how to operationalise public service delivery especially because they lack the necessary skills [14] and because many people remain suspicious of the government [15]. Public service delivery hence remains the traditional one way communication channel from the government. The participative paradigm sought after by the government remains a vague philosophical ideal. The specific case of the PAJA illustrates this.

The promulgation of the PAJA means that any person has the opportunity for their arguments to be aired to administrators before any decision affecting them is made. The PAJA only relates to decisions which negatively affect people's rights. This can be in terms of decisions taken that affect individuals directly, but also decisions affecting sections of the public, for example building a road through communal land. If the decision reached has a negative impact reasons in writing need to be given by the administrator within 90 days if requested by those affected. The objective is for it to be clear why the decision was made whether or not the affected people agree with the decision. For the administrator it implies five important things: that the administrator must follow fair procedures when making decisions; explain the decisions taken; explain any internal appeal process that may exist within the department; propose that the applicant can ask a court to review the decision, and; lastly, that written reasons for the decision are available if requested.

The PAJA is fundamentally about two main participatory decision-making processes within a social environment. The first is in terms of the affected people having the capacity to air their own views and give reasons as to why they should be given the requested service. The second relates to the capacity of the administrator to give reasons for the decisions made.

In terms of the capacity of people, affected people can challenge decisions if the correct procedure was not conducted and as such can hold administrators accountable for decisions which negatively affect them. However, such requests for decisions must be in writing and within 90 days of a negative decision. Special provision for appeals is admissible for certain government sections for example the Department of Home Affairs which has an Appeal Board, or for judicial review in court. However, given the expenses of judicial requirements a number of alternatives are suggested by the Department of Justice: writing a letter to the relevant Minister or DirectorGeneral, finding NGOs, CBOs and Paralegals in the area that could assist, contacting the Public Protector in cases where corruption is suspected, using the Human Rights Advice Line, Legal Aid Board and Justice Centres. The alternatives assume affected people have the capacity to develop coherent arguments.

In terms of the administrator, there are two clear procedures to follow: before taking a decision tell the people whose rights are affected what they plan to do and give them time to reply, and; after taking a decision, provide a clear statement on the decision made, information on any internal appeal and review process, and inform the affected people that they can request reasons for the decision.

In the next section we outline the role that specialised ICT, Decision Support Systems, could play in facilitating dialogue between administrators and affected people according to the PAJA.

\section{IS SUPPORTED DECISION MAKING PARADIGMS}

Decision Support Systems (DSS) offer a medium through which communication between administrators and affected people can be enhanced [16, 17]. Decision Support Systems are specialised types of ICT designed to make more efficient the decision-making abilities of organisations at the management and operational level [18].

However, the current approach used by administrators as shown in Section 2 follows the rather linear conventional DSS paradigm of;

- problem recognition

- $\quad$ problem definition

- alternatives generation

- evaluation of alternatives

- decide on best alternative and

- implement the decision

The linear approach ignores the socially oriented contexts in which decisions are taken. IS researchers investigating DSS are increasingly becoming critical of the past a-contextual stance of DSS [18, 2001, 19-22]. Mitroff and Linstone's [23] 
multiple views approach and Kaner and Lind's [24] participatory decision-making paradigm shed new light on understanding how the complexity of individuals and social issues can be addressed in a participatory manner.

The multiple views approach has been drawn on in various disciplines including Information Systems (IS). For example to understand social problems during efforts to address poverty in developing country contexts [25]; to elicit multiple perspectives during requirements gathering [26]; in bringing out individual values attached to decisions in new business environments [27]; to assist students to think deeper and reflectively [28]. The multiple views approach offered the capability for handling the complexity associated with communication of decision-making according to the PAJA.

Courtney [1] draws from the multiple views approach to argue for the need of a new paradigm of decision making within DSS as contexts get more complex and ill-structured. The complexity is largely attributable to the global nature of business, the increasing demand for knowledge driven decisions, and the call for more ethical/socially responsible business practices. The implications on DSS are that data from outside the organisation, often social data, is also required while making decisions. Courtney [1] hence postulates that the conventional DSS decision-making process is inadequate to deal with complex problems as its emphasis is on model development and the reduction of the decisions to alternative technical/mechanistic solutions. A more holistic approach to DSS is required where broad organisational, social and personal perspectives and ethical and aesthetic considerations can be included along with the traditional technical perspective (Fig. 1):

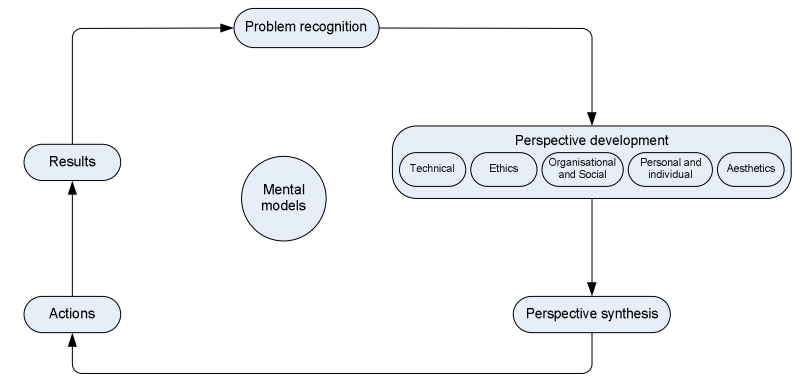

\section{FIG. 1 COURTNEY'S NEW DECISION-MAKING PARADIGM FOR DSS (COURTNEY, 2001)}

While the conventional approach to DSS moves from problem recognition into problem analysis, Courtney's [1] new decision-making paradigm (Figure 1) moves to a process of developing multiple perspectives on the nature of the problem. Courtney [1] prescribes that different tools and techniques can be used for the perspective development process but does not specify which tools may be more adequate than others. The mental modes determine what data and what perspectives we examine and how. These different perspectives focus on different essential aspects or parts of a problem: Technical-T (the analytical aspects of a problem); Organisational and Social - O (societal and occupational views); Personal and individual P (personal dispositions); ethical (morals), and; aesthetics (in its subjectiveness as to what constitutes beauty). This paradigm aims to: "...recognize the connectedness of things in the universe, especially of complex social problems. The non-separability and irreducibility of elements in complex problems and issues is recognized. The development of multiple perspectives is the very core of UST [Unbounded Systems Thinking]. A critical aspect of developing multiple perspectives is open, honest, effective dialogue among all relevant stakeholders in the problem involved. Managers in such an environment must be careful to respect the rights and viewpoints of the parties involved, and be open and honest themselves in order to gain the trust of those who will be affected by the decision" (Courtney, 2001 p.29).

Methodologically Courtney's [1] approach falls short in that it does not prescribe a method of getting the multiple views. However, Kaner \& Lind [24] offer possibilities on getting these multiple views during decision-making:

- Allow full participation - give every member of the group the freedom to express their views by encouraging anonymity

- Encourage mutual understanding - urge each member to accept and acknowledge the legitimacy of other members contributions as expressions of their needs and goals

- $\quad$ Reach inclusive solutions - involve every member in generating solutions

- Share responsibility - assign each member a role in implementing the solution

In the next section, we discuss how the multiple views approach was adopted as part of a DSS that encourages participative feedback on existing government services, and as a means to strengthen communication channels and capabilities for administrators with people in communities.

\section{CASE STUDY}

The paper is based on the second authors experience in a six year longitudinal interpretive research project entitled webbased Collaboration and thinkLets. The aim of the research project was to identify and harness opportunities for sustained collaboration and interaction between administrators and communities through the use of web-based Group Support System tools in the context of South Africa. Group Support Systems (GSS) are a specialised type of ICT designed to facilitate groups of people working together [29]. The research questions guiding the project concerned the features needed in web-based collaboration tools and how interfaces can be designed to enable citizens to interact effectively with government and public bodies in South Africa. The research was conducted through ICT facilitated role-playing exercises based on case scenarios in workshop settings. The purpose of the workshops was to raise awareness about the process involved in the implementation of the PAJA and to demonstrate the possibilities for the use of ICT to support the PAJA process simulated.

Three field locations were co-opted as research sites for the PAJA Project in 2005, and over the three years managed to retain the same research participants (Table 2.2). Lebotloane is 
in the North West Province and the research was hosted by the Lerethlabetse Multi-Purpose Community Centre (now called the Lerethlabetse Thusong Service Centre); Siyabuswa is in the Mpumalanga Province and the research was hosted by the Siyabuswa Education Improvement and Development Trust (SEIDET). The University of Pretoria is in the Gauteng Province and the research was hosted by the Department of Informatics.

TABLE I. RESEARCH PARTICIPANTS AT THE RESEARCH SITES

\begin{tabular}{|c|c|c|c|}
\hline & Lebotloane & Siyabuswa & $\begin{array}{c}\text { University of } \\
\text { Pretoria }\end{array}$ \\
\hline $\begin{array}{l}\text { Province where } \\
\text { Research } \\
\text { Participants came } \\
\text { from }\end{array}$ & North West & $\begin{array}{l}\text { Mpumalanga } \\
\text { Limpopo }\end{array}$ & Gauteng \\
\hline $\begin{array}{c}\text { Number of } \\
\text { Research } \\
\text { Participants (2005) }\end{array}$ & 29 & 22 & 8 \\
\hline $\begin{array}{c}\text { Number of } \\
\text { Research } \\
\text { Participants (2006) }\end{array}$ & 24 (1 new) & 12 & 8 (1 new) \\
\hline $\begin{array}{l}\text { Number of } \\
\text { Research } \\
\text { Participants } \\
(2007 / 8)\end{array}$ & 16 & 18 & 4 \\
\hline
\end{tabular}

The common denominator in selecting the research sites was a solid institutional base and the availability of computers. Since the PAJA Project was a longitudinal research project, cross-institutional linkages could provide better grounds for long term sustainability and such institutions are usually already established within their communities. Since the limited research funding did not include the provision of computers it meant that the host institutions needed to have an existing computer infrastructure.

Over the period 2005 to 2008, one workshop at each site every year was held, making a total of nine workshops over the three years. The workshop activities were maintained across the three sites in each research year (Table 2). Data were collected at every workshop activity using different data collection instruments (Table 2).

TABLE 2: PAJA PROJECT WORKSHOP STAGES \& DATA COLLECTION INSTRUMENT

\begin{tabular}{|c|c|}
\hline Workshop Activity & Data Collection Instrument \\
\hline Social interactions & \multirow{3}{*}{ - Video Coverage } \\
\hline $\begin{array}{l}\text { A description of the PAJA Project } \\
\text { and its research objectives }\end{array}$ & \\
\hline Explanation of the PAJA Act & \\
\hline Practical session on PAJA Act & $\begin{array}{c}\bullet \quad \text { Video Coverage } \\
\text { - } \quad \text { Electronic logs of the sessions } \\
\text { when using the ICT }\end{array}$ \\
\hline Formal Research feedback & $\begin{array}{c}\text { - Questionnaires } \\
\text { - Video Coverage (Question and } \\
\text { Answer Session) } \\
\text { - } \quad \text { PAJA Project Questionnaire }\end{array}$ \\
\hline
\end{tabular}

Social Interactions was where each research member and research participant introduced himself at each workshop. The exceptions were new people who were guests of the PAJA
Project or community members with a high social and/or political profile. This latter people were introduced by others. The leaders of the host sites were given the honour of chairing all non-academic formalities which included opening and closing the workshop and the social interactions.

The second activity was an outline of the research objectives. The PAJA Project leader at each workshop ensured that $\mathrm{s} /$ he explained the aims of the research in creating awareness of the PAJA Act and the desire that the research participants might be empowered to help themselves and others when dealing with government.

The third activity in the workshops of 2005 and 2006, was where the background of the PAJA Act was given to help participants understand the purposes of the Act, and the requirements and instances in which the Act can be invoked (Table 4.3). In 2005, the training was conducted in Siyabuswa and Lebotloane by two legal experts who had been previously involved in PAJA training across South Africa and had experience in the application of the Act. The Justice College expert explained the historical roots of the PAJA, the present implementation strategies of the PAJA, and expressed some challenges being experienced. The Master of the High Court illustrated the PAJA using examples that are dealt with at the High Court. At the University of Pretoria, the experts were not required as the research participants had already received training on the Act. Only a recap of the PAJA was given for the sake of those who might have forgotten what had been explained a year earlier. In 2007/8, the PAJA Act was not explained.

Practical Session on PAJA Act followed the brief overview of the Act. In 2005 and 2006, real case scenarios from previous research in this area [15] were used to simulate interaction between a government administrator and a citizen who had been affected by administrative action. In 2007 (2008) a pre-formatted example used by the government in training its administrators on how to implement the PAJA was used. The practical session followed the same pattern; the researcher would hand out the following materials to the research participants:

- A shortened copy of the PAJA requirements for government administrators.

- A shortened copy of the PAJA requirements for citizens.

- The case scenario and the rejection letter received by Grace and Anna from the government.

The researcher would then read through the case scenario along with the participants to ensure the case was well understood by all the participants. If there were any questions to clarify the case scenario, the researcher answered them. There were rarely any questions. The researcher then would ask the research participants to volunteer as either a government administrator or the affected person. The researcher then further sub-divided the administrator and affected citizen groups into smaller groups, depending on the number of computers available to be used. Each smaller group 
would then assume a role as either an affected person or the government administrator.

The instructions were that in each of the smaller groups they were to discuss amongst themselves how to respond to the other group. The smaller groups then proceeded to the computers in the computer lab. When at the computer the researcher would ask if there was anyone who was not able to operate the computer on behalf of the group. In the rare event that there was no person in the smaller group who knew how to use the computer, a student researchers was appointed to assist that group.

The computer simulation would then start with the researcher asking the affected person to discuss in 10 minutes how they should respond to the administrator. After seven minutes the affected person had to type on the computer what the group had decided and then submit it to the administrator. Similarly the administrator was asked to take 10 minutes to consider a response to the affected person, asking the administrator to ensure that they discussed the PAJA Act guidelines so they could give an appropriate answer to the query they had received from the affected person. After seven minutes the administrator was asked to type their answer and submit it. Three sets of correspondence between the affected person and the administrator were allowed which fitted in the hour allowed for this activity

Activity 5 concerned the elicitation of formal research feedback. Before the close of the workshops, there were three research feedback sessions. The first was a discussion where all parties came together, i.e. the researchers and the research participants, and discussed the experiences of the PAJA Act while using the computer. In the second feedback session the research participants recorded their experiences of the workshop individually on a piece of paper. Anonymity was allowed to enable free expressions. The final feedback session requested participants to openly offer their opinions and observations on anything they wished to comment on. Most people said they were beginning to understand why some of the requests by citizens are rejected and why some administrators are not responsive. They said they began to understand government better and some of the government responses which they often had taken for granted.

In the next section, we analyse the findings of the research through the lens of Kaner and Lind's [24] criteria for including the social context during decision-making and gaining multiple perspectives on the nature of the role-playing exercises.

\section{DISCUSSION:}

\section{A. Allow full participation}

The initial plan during the role-playing exercises was to have each individual use an own computer. However, many of the computers failed and people had to work in smaller groups of a maximum of 5 people. People had been given the opportunity to choose whether to play the role of an administrator or that of an affected person. It was interesting that people preferred to work in groups rather than individually. Many of the individuals were unfamiliar with using computers and preferred the safety of working with other people. Within the groups it was noticed that people were able to openly share their views on the decision that the administrator had taken and then discuss it before reaching a mutual answer. It was strange that there did not seem to be any contentions among the small groups of people.

It was also the intention to switch on anonymity for every individual but now that they worked in smaller groups, it was rather not practical to have anonymity. Hence, each smaller group knew which other group it was directly interacting with. Anonymity did not seem to have been important.

Both the administrators and affected people groups appreciated the capability of computer skills to primarily facilitate communication with other community members anonymously even though some were not familiar with computers. ICT does not have intrinsic value in itself but it is when it is used that it can lead to more productive efforts. The persistence to use the ICT as a communication channel despite the lack of exposure previously to ICT shows the determination to achieve an end using the best available means.

\section{B. Encourage mutual understanding}

The purpose of the research was to identify ICT opportunities for collaboration between administrators and communities. It was clear as part of the communication that prior to the interaction, there was a lack of clarity for the participants (both administrators and affected people groups) on the PAJA, what they are entitled to (affected people) or what their responsibilities are (administrators). But after the first set of communications between the groups, the affected groups began to understand what was expected of them, while the administrator groups similarly began to understand the perspective of the affected groups. In some instances, the groups required more than three cycles of communication to reach mutual understanding. In other instances, despite the affected groups understanding what was expected from them and the administrator group understanding the perspective of the affected groups, there was a deadlock in regards the decision reached by the administrators. In either case there was mutual understanding on the fundamentals of the decision.

"It has helped with the procedures of AJA. I didn't know about AJA until I attended the workshops. It has got good implications for the survival of the citizens and upholding our democracy" (need some respondent number, even if just respondent 1 workshop 1)

"For a person in the street, it is very difficult and this means that people can get to know the procedures and the requirements of the AJA."

\section{Reach inclusive solutions:}

As seen in the previous discussion, the solutions reached were a better understanding of the PAJA and an understanding of the different roles and responsibilities. Everyone was offered the opportunity to contribute to the decision even if there might not have been agreement on the final decision. An important aspect of participatory decision-making, as expected by the PAJA, is to set realistic expectations of all those involved in the decision making exercise [24] otherwise clients 
may approach for a service with unrealistic expectations and leave disgruntled and disillusioned.

"Yes, it will reduce long queues and inconvenience for the sick and aged. These people will get quick responses and will know beforehand what is expected of them for making applications to government for services."

There was recognition of the importance of being prepared for what to expect on the part of the citizen claiming the service

"It makes understand better the different grants or support we can have from the government and how we can apply them"

"Many cases, the issue is about different departments, not all the departments have the internal appeals mechanism especially Housing. People wait for their application for years and still get rejected without any authentic reasons. Our organisation is working under scarce resources and overworked staff so we are unable to do proper follow-ups or use PAJA effectively”.

"Yes, it was when I attempted to make a booking for a drivers licence, I was denied the service on the pretext that the computers were off line while they were actually processing forms specific from driving schools. I should have been informed on where to go and who to contact other than them."

The quality of any decision is directly related to the clarity and knowledge about an issue that people participating in arriving at the decision have [30].

"It opens up our minds as far as certain Adminstrative Acts are concern that we did not know about. It also changes the perception of adminstrators that do not treat citizen with respect to their rights."

\section{Share responsibility:}

The process of allowing each group to express their perspectives enabled a sharing of responsibility in reaching decision. Understanding the roles and responsibilities meant that every group became aware of what was expected and what was perceived. Hence, DSS was useful in allowing a shared responsibility amongst the administrators and affected people.

\section{E. A model for DSS in Administrative decision-making}

In summary, the potential of GSS to enable and capture multiple perspectives during the process of decision-making is captured in Table 3 below:

TABLE 3: MODEL FOR ADMINISTRATIVE DECISION-MAKING

\begin{tabular}{|c|l|l|}
\hline & DSS Facilitators & DSS Potential distortions \\
\hline $\begin{array}{c}\text { Allow full } \\
\text { participation }\end{array}$ & & \\
\hline $\begin{array}{c}\text { Encourage mutual } \\
\text { understanding }\end{array}$ & & \\
\hline $\begin{array}{c}\text { Reach inclusive } \\
\text { solutions }\end{array}$ & & \\
\hline $\begin{array}{c}\text { Share responsibility } \\
\end{array}$ & & \\
\hline
\end{tabular}

\section{CONCLUSION}

We recognised the lack of capacity in DC communities to adequately participate with government in participatory governance, much less therefore in participatory e-governance. Individuals in DCs are generally limited in their ability to present their arguments with the persuasive versatility required to influence how decisions that are made but in groups, are better able to present their arguments.

For an inclusive and collaborative approach to service delivery there should be mutual/shared understanding and agreement on the solution. This goes beyond justifying a decision. In this case communication is the means of not just finding out what administrators have previously decided or learned, but a process in which opinion and consensus is created by the process of debate itself. To do this people must have the capacity and space/place to express themselves openly and freely and must accept the outcome of rational argument requiring all communication in writing in a traditional orally based culture does not achieve this. For participatory decision making to occur, there is the need for a common understanding of terms, visions and cultural practices. Communication involves much more than the language used between actors, and incorporates a complex network of social relationships [31]. The process of communication will not remove all the barriers, but the attainment of critical reflection of individuals, through which emancipation can occur.

"The underlying utopia is the emancipatory idea of a community of free and self-responsible citizens coming together and seeking to achieve consensus on matters of public (non-private) concern by means of argumentative, oppressionfree will-formation and democratic majority vote. [32, p.3]"

In terms of the PAJA the conventional approach to DSS decision-making will not be useful in that government service delivery is complex. Decisions are being made in a complex and changing environment which is fundamentally about social processes and fostering cooperative environments. Thus the implementation of PAJA must recognise that DSS can assist in some way, but only if they form part of a broader systems approach to its implementation. In terms of decisions impacting on society, as Phahlamohlaka and Roode [33] note, conventional decision theory focuses on limited cognitive information processing capability of individual decision makers and not on the social aspects of the decision making process. In this sense Courtney [1] and Kaner \& Lind's [24] participatory decision-making paradigm is a suitable paradigm in which to view the implementation of the PAJA aided by ICT. This also has implications on the decisions made are justified in such an organisational context.

Courtney [1] and Kaner \& Lind's [24] participatory decision-making paradigm can be used to explore how the generation of multiple perspectives can foster the creation of the inclusive e-governance or collaborative environment which we need to achieve if PAJA in particular, and Batho Pele in general, are to be implemented to lead to improved public service delivery. 


\section{REFERENCES:}

[1] J. F. Courtney, "Decision making and knowledge management in inquiring organizations: toward a new decision-making paradigm for DSS," Decision Support Systems vol. 31, pp. 17-38, 2001

[2] E.-R. Staiou and D. Gouscos, "Socializing E-governance: A Parallel Study of Participatory E-governance and Emerging Social Media," in Comparative E-Government. vol. 25, C. G. Reddick, Ed., ed: Springer New York, 2010, pp. 543-559.

[3] H. Corder, et al., Global administrative law : development and innovation. Cape Town: Juta, 2009.

[4] Republic of South Africa, "Report on the State of the Public Service 2001," P. S. Commission, Ed., ed: South African Government Information, 2001.

[5] Republic of South Africa, "State of the Public Service Report - 2002," P. S. Commission, Ed., ed: South African Government Information, 2002.

[6] Republic of South Africa, "State of the Public Service Report - 2004," P. S. Commission, Ed., ed: South African Government Information, 2004.

[7] Republic of South Africa, "State of the Public Service Report - 2005," P. S. Commission, Ed., ed: South African Government Information, 2005.

[8] Republic of South Africa, "State of Public Service Report 2006: Assessing the Capacity of the State to Deliver," vol. 2006, Public Service Commission, Ed., ed: South African Government Online, 2006, pp. $1-76$.

[9] Republic of South Africa, "State of Public Service Report 2007: Promoting Growth and Development through an Effective Public Service.," P. S. Commission, Ed., ed: South African Government Online, 2007, pp. 1-85

[10] S. Askvik and N. Bak, Trust in public institutions in South Africa. Aldershot, Hants, England ; Burlington, VT, USA: Ashgate, 2005.

[11] N. F. Rakate, "Transformation in the South African Public Service: The Case of Service Delivery in the Department of Health," Magister Administrationis Master, Faculty of Economic \& Management Science, University of Pretoria, Pretoria, 2006.

[12] L. Harris. (2006) SITA calls on private sector for help. Computing SA [Conference Review Report]. 10-11.

[13] N. Legoabe, "MPCCs as vehicles for service delivery and development communication," in Service Delivery Review vol. 3 , Government Communication and Information System, Ed., ed: Department of Public Service and Administration, 2004, pp. 90-92.

[14] Deputy President, "Joint Initiative on Priority Skills Acquisition Report Mar - Dec 2006," Department of Labour, Ed., ed: Joint Initiative on Priority Skills Acquisition, 2007, pp. 1-30.

[15] H. Twinomurinzi and L. J. Phahlamohlaka, "Enhancing procedural fairness in administrative action of the Administrative Justice Act of South Africa using web-based Group Support Systems," in Second Conference on Online Deliberation: Design, Research, and Practice / DIAC-2005, California, 2005.

[16] J. W. Dickey and I. A. Birsall, "Information, Technology, and Decision Making," in Handbook of Decision Making, G. Morcol, Ed. ed Boca Raton: CRC/Taylor \& Francis, 2007, p. 638 p.

[17] M. Yildiz, "Information, Technology, and Decision Making," in Handbook of Decision Making, G. Morcol, Ed., ed Boca Raton: CRC/Taylor \& Francis, 2007, p. 638 p.

[18] A. Gopal and P. Prasad, "Understanding GDSS in Symbolic Context: Shifting the focus from Technology to Interaction," MIS Quarterly, vol. 24 , pp. 509-546, 2000 .

[19] N. Kock, "What is E-Collaboration?," The International Journal of ECollaboration, vol. 1, pp. i-vii, January-March 20052005.
[20] R. O. Briggs, et al., "Collaboration Engineering with ThinkLets to Pursue Sustained Success with Group Support Systems," Journal of Management Information Systems, vol. 19, pp. 31-64, Spring 2003 2003.

[21] A. R. Dennis, et al., "Understanding fit and appropriation effects in Group Support Systems via Meta-Analysis," MIS Quarterly, vol. 5, pp. 167-193, 2001.

[22] G. J. Vreede, De, "Facilitation of Electronic Collaboration with Group Systems," D. o. I. INF 821 Class Lecture, University of Pretoria, Ed., ed. Pretoria, 2006.

[23] I. I. Mitroff and H. A. Linstone, The unbounded mind : breaking the chains of traditional business thinking. New York, N.Y: Oxford University Press, 1993.

[24] S. Kaner and L. Lind, Facilitator's guide to participatory decisionmaking. Philadelphia: New Society, 1996.

[25] M. Turpin, et al., "The Multiple Perspectives Approach as a framework to analyse social systems in a developing country context," in Proceedings of the 10th International Conference on Social Implications of Computers in Developing Countries, Dubai, United Arab Emirates, 2009.

[26] L.-K. Soonhwa, et al., "A requirements elicitation framework and tool for sourcing business-IT aligned e-services," presented at the Proceedings of the 2010 ACM Symposium on Applied Computing, Sierre, Switzerland, 2010

[27] D. Hall and R. Davies, "Engaging multiple perspectives: A valuebased decision-making model " Decision Support Systems, vol. 43, pp. 1588-1604, 2007

[28] L. Houghton and A. Ruth, "Making Information Systems less Scrugged: Reflecting on the Processes of Change in Teaching and Learning," Journal of Information Technology Education, vol. 9, 2010 .

[29] I. Zigurs and B. K. Buckland, "A Theory of Task/Technology Fit and Group Support Systems Effectiveness," MIS Quarterly, vol. 22, pp. 313-334, 1998.

[30] T. L. Griffith, et al., "Facilitator influence in Group Support Systems: Intended and Unintended Effects," Information Systems Research, vol. 9, pp. 20-36, 1998.

[31] J. Habermas, The Theory of Communicative Action, Volume 1: Reason and the Rationalization of Society Cambridge: Polity Press, 1987.

[32] K. Ivanov, "Critical systems thinking and information technology some summary reflections, doubts, and hopes through critical thinking critically considered, and through hypersystems," Journal of Applied Systems Analysis, vol. 18, pp. 39-55, 1991.

[33] L. J. Phahlamohlaka and J. D. Roode, "Justification of Group Decisions: A Case Study of User Training in Group Support Systems Applications," in Proceedings of the Ninth European Conference on Information Systems, Bled, Slovenia, 2001 